\title{
The ACTN3 R577X nonsense allele is under-represented in elite- level strength athletes
}

\author{
Stephen M Roth ${ }^{\star}, 1$, Sean Walsh ${ }^{1}$, Dongmei Liu ${ }^{1}$, E Jeffrey Metter ${ }^{2}$, Luigi Ferrucci ${ }^{2}$, and Ben \\ F Hurley ${ }^{1}$ \\ 1Department of Kinesiology, University of Maryland College Park School of Public Health, College Park, \\ $M D, U S A$
}

2Clinical Research Branch, National Institute on Aging, Harbor Hospital, Baltimore, MD, USA

\begin{abstract}
Previous reports have shown a lower proportion of the ACTN3 X/X genotype (R577X nonsense polymorphism) in sprint-related athletes compared to the general population, possibly attributed to impairment of muscle function related to $\alpha$-actinin-3 deficiency. In the present study, we examined the frequency of the $\mathrm{X} / \mathrm{X}$ genotype in both Black and White elite-level bodybuilders and strength athletes in comparison to the general population. A reference population of 668 Whites (363 men and 305 women) and 208 Blacks (98 men and 110 women) was genotyped for the ACTN3 R577X polymorphism. Strength athletes ( 52 white and 23 black; 4 women) consisting predominantly of world class and locally competitive bodybuilders, and elite powerlifters were recruited and similarly genotyped. Significantly lower X/X genotype frequencies were observed in the athletes (6.7\%) vs controls $(16.3 \% ; P=0.005)$. The $\mathrm{X} / \mathrm{X}$ genotype was significantly lower in White athletes $(9.7 \%)$ $v s$ controls $(19.9 \% ; P=0.018)$. No black athletes $(0 \%)$ were observed with the $\mathrm{X} / \mathrm{X}$ genotype, though this finding only approached statistical significance $v s$ controls $(4.8 \% ; P=0.10)$. The results indicate that the ACTN3 R577X nonsense allele (X) is under-represented in elite strength athletes, consistent with previous reports indicating that $\alpha$-actinin-3 deficiency appears to impair muscle performance.
\end{abstract}

\section{Keywords}

skeletal muscle; polymorphism; muscle strength

\section{Introduction}

In skeletal muscle, $\alpha$-actinin proteins ( $\alpha$-actinin- 2 and $\alpha$-actinin- 3 ) are an important structural component of the $\mathrm{Z}$ disc, where they anchor actin thin filaments, helping to maintain the myofibrillar array. 1,2 In humans, $\alpha$-actinin- 2 is expressed in all skeletal muscle fibers, while $\alpha$-actinin-3 is expressed only in type 2 fibers. ${ }^{3}$ The $\alpha$-actinin-3 gene (ACTN3) has attracted considerable attention recently due to a frequent nonsense polymorphism (R577X) that may influence muscular performance. ${ }^{4}$ The $\mathrm{R} 577 \mathrm{X}$ polymorphism is not associated with overt muscle disease despite the complete absence of $\alpha$-actinin- 3 protein in individuals carrying the $\mathrm{X} / \mathrm{X}$ genotype. ${ }^{3}$ Subsequent studies addressed the question of whether the $\mathrm{X} / \mathrm{X}$ genotype may somehow affect muscle function in otherwise healthy individuals, especially for movements involving high force, given the protein's localization to only type 2 muscle fibers. 5,6

*Correspondence: Dr SM Roth, Department of Kinesiology, University of Maryland, 2134 HHP Building, College Park, MD 20742,

USA. Tel: + 1301405 2504; Fax: + 1301405 5578; E-mail: sroth1@ umd.edu. 
Yang et $^{7} \mathrm{l}^{7}$ first reported in 2003 an under-representation of the X/X genotype group in elite sprint athletes; those findings have been replicated in Finnish and Greek populations 8,9 and extended to show lower sprint performance in X/X genotype carriers in a Greek population. 10 These results indicate an advantage for sprint-related athletes expressing the $\alpha$-actinin-3 protein compared to $\mathrm{X} / \mathrm{X}$ athletes deficient in the protein.

In the present case-control study, we sought to determine if the previous findings of underrepresentation of the $A C T N 3 \mathrm{X} / \mathrm{X}$ genotype in sprint-related athletes would be extended to other primarily anaerobic athletes such as bodybuilders and powerlifters.

\section{Methods}

\section{Subjects}

Subjects included 75 elite-level bodybuilders ( $n=18$ ranked in the top 100 worldwide), powerlifters, and college level strength athletes from across the United States, and 876 men and women from the general population of the Maryland region participating in the Baltimore Longitudinal Study of Aging. The recruitment strategies and characteristics of the strength athletes have been described previously in detail; ${ }^{11}$ no direct physiological data are available on the athletes. The Baltimore Longitudinal Study of Aging is comprised of healthy men and women across the adult age-span (19-90 years); very few of the Baltimore Longitudinal Study of Aging subjects participate in strength training. ${ }^{12}$ All subjects were either White or Black by self-report (Table 1). Written informed consent was obtained from all subjects under protocols approved by the Institutional Review Boards of the University of Maryland, Johns Hopkins Bayview, and Harbor Hospital.

\section{DNA and genotyping}

All subjects were genotyped for the ACTN3 R577X polymorphism using restriction digest methods described previously ${ }^{6}$ on DNA collected from whole blood. Sequence verified control samples of all three genotypes were used for all assays.

\section{Statistics}

One-tailed $\chi^{2}$ tests were performed to compare genotype frequencies between athletes and controls. Because X-allele frequencies are known to differ between Whites and Blacks, ${ }^{6}$ analyses were performed both in the total group and within each race group separately. Statistical significance was accepted at $P<0.05$.

\section{Results}

The sex and race information of the 75 strength athletes and 876 control subjects is listed in Table 1. No significant genotype frequency differences were observed between men and women within the control group. Hardy-Weinberg equilibrium (HWE) calculations showed no deviation from expected frequencies in controls, but deviation was observed in the total athlete group $(P=0.001)$, White athletes $(P=0.01)$, and Black athletes $(P=0.06)$. A significantly lower frequency of the $\mathrm{X} / \mathrm{X}$ genotype was observed in the athletes $(6.7 \%)$ compared to controls $(16.3 \% ; P=0.005$; Table 2$)$. Within race groups, the $\mathrm{X} / \mathrm{X}$ genotype was significantly lower in White athletes $v s$ controls $(P=0.018)$. No Black athletes were observed with the $\mathrm{X} / \mathrm{X}$ genotype, though this finding only approached statistical significance $(P=0.10$; Table 2). 


\section{Discussion}

The present report is the first to demonstrate a lower proportion of the ACTN3 R577X X/X genotype in elite-level strength athletes. The findings extend previous reports showing lower frequency of the $\mathrm{X} / \mathrm{X}$ genotype in sprint-related athletes of various events. The athletes in the present study were predominantly male, so whether the results extend to female elite strength athletes, who differ from similarly trained males, ${ }^{13}$ is uncertain.

The present study relied on bodybuilders, powerlifters, and other strength athletes, many of whom were highly competitive within their discipline (eg, 18 of them were ranked among the top 100 bodybuilders worldwide), while previous cross-sectional studies of ACTN3 genotype have examined sprinters, short-track cyclists, etc. ${ }^{7-9}$ The strength athletes exhibit extreme muscle hypertrophy, ${ }^{14,15}$ with performance measured either as physical appearance or singlerepetition maximal force production (strength), rather than the multiple contraction events typical of sprint-related athletes. ${ }^{7-10}$ Because the $\alpha$-actinin protein is important for maintaining the myofibrillar array within the muscle fiber, ${ }^{1,2}$ deficiency of the protein may be important for maintaining the contractile protein arrangement across multiple contractions involving type 2 muscle fibers, as can be inferred from previous studies; ${ }^{7-10}$ the importance of single-contraction performance (eg, one-repetition maximum) is unknown. In this regard, strength athletes may demonstrate a lower proportion of X/X genotype compared to controls based more on their training regimens of multiple repetitions of heavy resistance ${ }^{16}$ compared to other athletes, rather than on their performance outcomes. Alternatively, recently published data by Vincent et al ${ }^{17}$ indicate altered morphology of type 2 fibers in X/X carriers. Preferential hypertrophy of type 2 fibers has been observed in bodybuilders and strength athletes, ${ }^{14,18}$ so the findings of Vincent et $\mathrm{al}^{17}$ may represent another mechanism explaining our findings. The mechanisms underlying our findings will require further testing in future studies. No differences were noted in allele frequency between bodybuilders and powerlifters, though sample size limitations prevented a conclusive analysis in this regard.

The finding of low frequencies of the X/X genotype in Black individuals in the present study is consistent with the previous finding of low $\mathrm{X}$-allele frequencies in African-descent populations. ${ }^{6}$ While no Black athletes carried the X/X genotype in the present study, this finding only approached statistical significance compared to controls, due in part to sample size limitations in the Black athlete group. Thus, verification of this result is warranted. The finding of significant deviations from HWE in the athletes but not in controls is consistent with a true genotype association. 19

That higher R/R genotype frequencies were observed in controls compared to athletes does not have a clear explanation, nor do we know if the data are meaningful. The known biology of the R577X polymorphism would suggest a recessive model, with $\alpha$-actinin-3 deficiency present in $\mathrm{X} / \mathrm{X}$ carriers only. ${ }^{3}$ A recently developed Actn 3 -knockout mouse $\mathrm{e}^{20}$ and the data from humans showing altered muscle fiber morphology in $\mathrm{X} / \mathrm{X}$ carriers ${ }^{17}$ are beginning to address the mechanisms underlying the functional differences observed in the present and previous studies.

While cross-sectional studies to date have consistently shown that the $\mathrm{X} / \mathrm{X}$ genotype is underrepresented in sprint-related athletes ${ }^{7-9}$ or associated with inferior performance, ${ }^{10}$ longitudinal studies have produced more mixed results. ${ }^{21,22}$ Additional studies are required to more completely address the influence of $\alpha$-actinin- 3 deficiency on muscular performance, especially focused on identifying the specific muscle phenotypes that are most affected by the deficiency (eg, multiple $v s$ single-contraction measures). The ACTN3 findings reported here extend previous reports showing lower $\mathrm{X} / \mathrm{X}$ genotype frequency in elite sprint-related athletes 
and provide further support for the hypothesis that $\alpha$-actinin-3 protein deficiency (X/X genotype) impairs muscle performance.

\section{Acknowledgements}

We thank the volunteers who made this study possible. This research was supported by the Intramural Research Program of the NIH, National Institute on Aging, AG16205, AG21500, and AG22791.

\section{References}

1. Beggs AH, Byers TJ, Knoll JH, Boyce FM, Bruns GA, Kunkel LM. Cloning and characterization of two human skeletal muscle alpha-actinin genes located on chromosomes 1 and 11. J Biol Chem 1992;267:9281-9288. [PubMed: 1339456]

2. Blanchard A, Ohanian V, Critchley D. The structure and function of alpha-actinin. J Muscle Res Cell Motil 1989;10:280-289. [PubMed: 2671039]

3. North KN, Yang N, Wattanasirishaigoon D, Mills MA, Easteal S, Beggs AH. A common nonsense mutation results in $\alpha$-actinin-3 deficiency in the general population. Nat Genet 1999;21:353-354. [PubMed: 10192379]

4. MacArthur DG, North KN. ACTN3: a genetic influence on muscle function and athletic performance. Exerc Sport Sci Rev 2007;35:30-34. [PubMed: 17211191]

5. North KN, Beggs AH. Deficiency of a skeletal muscle isoform of alpha-actinin (alpha-actinin-3) in merosin-positive congenital muscular dystrophy. Neuromuscul Disord 1996;6:229-235. [PubMed: 8887951]

6. Mills MA, Yang N, Weinberger RP, et al. Differential expression of the actin-binding proteins, $\alpha$ actinin-2 and -3 , in different species: implications for the evolution of functional redundancy. Hum Mol Genet 2001;10:1335-1346. [PubMed: 11440986]

7. Yang N, MacArthur DG, Gulbin JP, et al. ACTN3 genotype is associated with human elite athletic performance. Am J Hum Genet 2003;73:627-631. [PubMed: 12879365]

8. Niemi AK, Majamaa K. Mitochondrial DNA and ACTN3 genotypes in Finnish elite endurance and sprint athletes. Eur J Hum Genet 2005;13:965-969. [PubMed: 15886711]

9. Papadimitriou ID, Papadopoulos C, Kouvatsi A, Triantaphyllidis C. The ACTN3 gene in elite Greek track and field athletes. Int J Sports Med. in press

10. Moran CN, Yang N, Bailey ME, et al. Association analysis of the ACTN3 R577X polymorphism and complex quantitative body composition and performance phenotypes in adolescent Greeks. Eur J Hum Genet 2007;15:88-93. [PubMed: 17033684]

11. Ferrell RE, Conte V, Lawrence EC, Roth SM, Hagberg JM, Hurley BF. Frequent sequence variation in the human myostatin (GDF8) gene as a marker for analysis of muscle-related phenotypes. Genomics 1999;62:203-207. [PubMed: 10610713]

12. Lindle RS, Metter EJ, Lynch NA, et al. Age and gender comparisons of muscle strength in 654 women and men aged 20-93 year. J Appl Physiol 1997;83:1581-1587. [PubMed: 9375323]

13. Alway SE, Brumbt WH, Gonyea WJ, Stray-Gundersen J. Contrasts in muscle and myofibers of elite male and female bodybuilders. J Appl Physiol 1989;67:24-31. [PubMed: 2759948]

14. Sale DG, MacDougall JD, Alway SE, Sutton JR. Voluntary strength and muscle characteristics in untrained men and women and male bodybuilders. J Appl Physiol 1987;62:1786-1793. [PubMed: 3597252]

15. Katch VL, Katch FI, Moffatt R, Gittleson M. Muscular development and lean body weight in body builders and weight lifters. Med Sci Sports Exerc 1980;12:340-344. [PubMed: 7453511]

16. Lemon PW, Tarnopolsky MA, MacDougall JD, Atkinson SA. Protein requirements and muscle mass/ strength changes during intensive training in novice bodybuilders. J Appl Physiol 1992;73:767-775. [PubMed: 1400008]

17. Vincent B, De Bock K, Ramaekers M. The ACTN3 (R577X) genotype is associated with fiber type distribution. Physiol Genomics. in press

18. Alway SE, Grumbt WH, Stray-Gundersen J, Gonyea WJ. Effects of resistance training on elbow flexors of highly competitive bodybuilders. J Appl Physiol 1992;72:1512-1521. [PubMed: 1592744] 
19. Wittke-Thompson JK, Pluzhnikov A, Cox NJ. Rationale inferences about departures from HardyWeinberg equilibrium. Am J Hum Genet 2005;76:967-986. [PubMed: 15834813]

20. MacArthur DG, Seto JT, Raftery JM, et al. Loss of ACTN3 gene function alters mouse muscle metabolism and shows evidence of positive selection in humans. Nat Genet 2007;39:1261-1265. [PubMed: 17828264]

21. Clarkson PM, Devaney JM, Gordish-Dressman H, et al. ACTN3 genotype is associated with increases in muscle strength in response to resistance training in women. J Appl Physiol 2005;99:154-163. [PubMed: 15718405]

22. Delmonico MJ, Kostek MA, Doldo NA, et al. The alpha-actinin-3 (ACTN3) R577X polymorphism influences knee extensor peak power response to strength training in older men and women. J Gerontol Med Sci 2007;62:206-212. 
Table 1

Sex and race sample sizes of the strength athletes and the general population control subjects

\begin{tabular}{|c|c|c|c|c|}
\hline & \multicolumn{2}{|c|}{ Race } & \multicolumn{2}{|c|}{ Sex } \\
\hline & White & Black & Female & Male \\
\hline Athletes (75) & 52 & 23 & 4 & 71 \\
\hline Control (876) & 668 & 208 & 415 & 461 \\
\hline
\end{tabular}




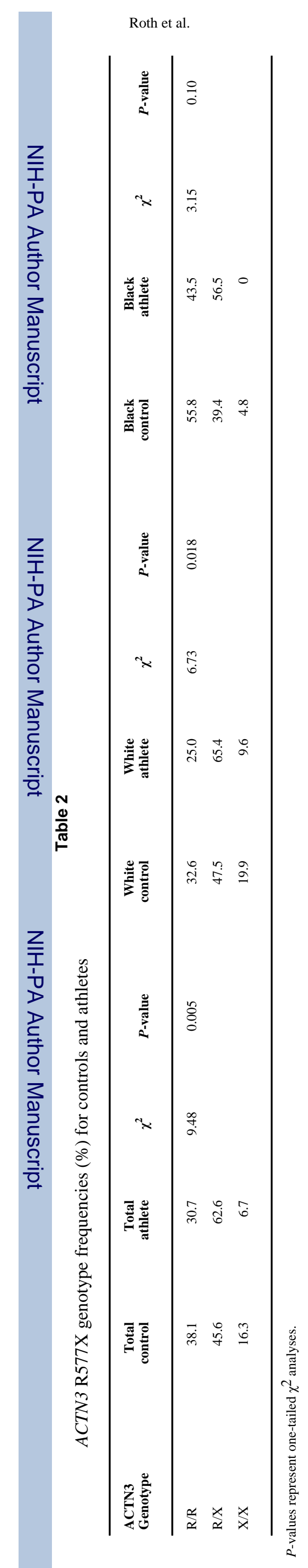

Page 7 